\title{
A Critical Evaluation of Santosh Kumar Yadav's Research and Publication Ethics
}

\author{
S M Fasiullah \\ Research Scholar \\ Department of English, \\ Maulana Azad National Urdu University \\ Hyderabad, India \\ smfasiullah@gmail.com \\ DOI: https://doi.org/10.24113/ijellh.v9i4.10986
}

\begin{abstract}
Research is an adventurous endeavor. It poses many challenges and difficulties. A person undertaking research needs supervision and guidance to avoid problems and successfully complete the research. A typical problem in the field of research is plagiarism. After University Grants Commission mandated universities and colleges to teach 2-credit course in "Research and Publication Ethics", a book with the same title authored by Dr. Santosh Kumar Yadav comes as a timely guidebook for thousands of research scholars from India and beyond. This study critically evaluates the book to bring out its merits and demerits.

Yadav's book is not only suitable for research scholars from various disciplines but also for librarians, academicians, educationists and researchers running different institutions. It explains different concepts at length and offers advice on effective implementation strategies of promoting research integrity at institutional level, minimizing plagiarism and publicizing research output for a wider reach through technological platforms. The book is extensive in information yet simple and precise in explanation.
\end{abstract}


Keywords: Research Ethics, Publication Ethics, Plagiarism, Santosh Kumar Yadav

1. Introduction

Research is a tedious task that tests endurance and patience while unraveling the very layers of knowledge and impressions that shape a person undertaking the research. Those desirous of conducting research have to, in essence, not only "re-search" to gain new knowledge but also rediscover, reevaluate and reorient their "self". The researcher's journey, or perhaps adventure, begins with a "postmortem" of his own personality. Lucky are the ones who join course work (a.k.a Pre-PhD), a first phase in the researcher's life which could be termed "mirror stage". The research, being a roller coaster ride with unforeseen challenges, requires "supervision" from learned beings specialized in various domains of knowledge. A general need for all budding researchers from across disciplines is a brainstorming on "How to conduct research?" and "How not to stumble during the research journey?" Thanks to India's University Grants Commission (UGC) for introducing a 2-credit paper titled "Research and Publication Ethics" from 2020 onwards to bring "awareness about the publication ethics and research misconduct" (v). Consequently, Maulana Azad National Urdu University (MANUU) has prescribed the aforementioned course beginning from 2020-21 academic year onwards for its research programs. In this context, a book authored by Dr. Santosh Kumar Yadav comes as a timely guidebook for thousands of research scholars from India and beyond. His book Research and Publication Ethics provides "ample information" regarding the subject through "various sources, organizations and research councils" (vi). The present study aims at critically evaluating this book by addressing following questions:
a. What is the relevance of this book?
b. Who are its expected readers?
c. How to avoid plagiarism in research work?
d. Does this book offer scope for improvement? 
In addition to addressing these questions, the study would bring into focus certain key ideas from the book for the benefit of readers. This study is partly undertaken in the spirit, as stated by the author: "Reviews and suggestions are cordially invited for the betterment of the book." (vi)

\section{Critical Evaluation of Research and Publication Ethics}

Santosh Kumar Yadav's book Research and Publication Ethics has appeared in its first edition in 2020, immediately after the UGC announced that it is mandating universities and colleges of the country to run a 2-credit course of the same topic. As a primary reading, the scholars of Department of English were asked to refer the book of Yadav.

2.1 What is the relevance of this book?

Santosh Kumar Yadav's book is published by Ane Books Pvt. Ltd and runs into 270 pages. The book is well-organized into chapters and subchapters. Twelve different chapters cover as many as one hundred and twenty-five topics. It includes most of the topics as suggested by the UGC in its letter such as "Philosophy and Ethics, Scientific Misconduct, Publication Ethics, Open Access Publishing, Databases and Research Metrics, and Publication Misconduct". It elucidates the very concept or philosophy of research: in short it is the "pursuit of truth" and more clearly it is a "resource for enabling us more effectively to achieve prescribed ends, but also an instrument of disturbance, disruption, and dissent challenging not only the answers to questions about our practice but also the questions which we ask." (22) The author argues that it was a mistake to consider ethics as "a universal or abstract science" because it was a field for practical wisdom rather than theoretical analysis (33). He goes on to state that research ethics has two fields within it: "research integrity and publication ethics." (27) In a similar way, an ethical problem has two sides as well. One is personal elements and the other is professional elements (29). The book deals with research integrity and publication ethics judiciously. 
2.2 Who are its expected readers?

A thorough reading of the book reveals that the intended readers of the book are not only research scholars from various disciplines but also librarians, academicians, educationists and researchers running different institutions. The book explains different concepts at length and offers advice on effective implementation strategies of promoting research integrity at institutional level, minimizing plagiarism and publicizing research output for a wider reach through technological platforms. The book is extensive in information yet simple and precise in explanation. For example, concepts of Impact Factor and h-Index (244$45 ; 248-49 ; 258)$, which are difficult to understand for non-mathematical background scholars, have been explained in simple terms and way in this book. A chapter titled "Open Access Publishing" gives as much information as a research may need to be aware of research, how it could be produced avoiding duplication and plagiarism, and reap the benefits of research output. So, this book is an easy read for anybody who is interested in carrying out research activity.

\subsection{How to avoid plagiarism in research work?}

Research is a complex process and tedious endeavor. The researcher may stumble during the research journey, and commit mistakes out of lack of awareness, inexperience, lethargy or unfamiliarity with publishing practices and technology. The author apprises researchers that: "Research needs to be honestly reported, shared with participants, not previously published, not plagiarized and duly credited to authors that make a contribution." (33) This brings up an important issue of plagiarism that dents the very spirit of researchers to carry out research. In fact, the researcher may feel confident of research provided he or she knows the danger beforehand. The book helps us understand the three forms of plagiarism: "cheating, non-attribution and patchwork writing" (220). The author explains that the first form of plagiarism is a deliberate act while the second one results from misunderstanding 
about academic conventions and inexperience, and the third occurs when the researcher puts together bits of assorted and copied text in an attempt to compose an unsatisfactory whole. (220) So, what is the way to avoid all these forms of plagiarism? This book answers it accurately. Before offering the solution, the author makes the researcher realize that referencing helps to "identify the evidence" (215) used in the research work and "accurate referencing will help us to avoid being accused of plagiarism." (218) According to the author, there are two ways to avoid plagiarism:

I. “Attempt to summarize or restate another person's work, theorize or ideas and give acknowledgement to that person. This is usually done by citing your sources and presenting a list of references."

II. "By always using quotation marks (or indicating lengthy quotations in the text) to distinguish between actual words of the writer and our own words. Once again, we should cite all sources and present full details of these in our list of references." (222)

Besides these two suggestions, the researcher may find subchapters titled "Detecting potential plagiarism" (232-33) and "Critical Analysis" (234-35) relevant for better understanding of the whole issue of plagiarism.

2.4 Does this book offer scope for improvement?

One may find the whole book being well-organized but somewhere across the pages there is lack of coherence intermittently. The book dedicates a whole subchapter on Harvard Naming Convention and skips detailed explanation of widely used style manuals APA and MLA (224-227). It follows a uniform style for listing works in "References" section (263-65) at the end but uses various styles for doing the same towards the end of each chapter. A glaring issue appears in examples cited for different referencing styles such as MLA, APA, MHRA, etc. All the examples for five different styles carry one or more errors (223). Also, a 
series of typographical errors creep into the text: "To ensures...To protects...To promotes..." (110-111); "It is well worth nothing..." (157); and different typefaces in pages 44 and 131. Apart from these errors, "Evaluation by Self-assessment" (69) heading could be modified to do away with redundancy. Above all, the book on research could have avoided citing "Wikiversity" on intellectual honesty as the source is a user-generated information platform. All these human errors result from expeditious publication, and could be minimized at the proofing and copyediting levels.

\section{Conclusion}

The book on Research and Publication Ethics is timely and relevant as it covers all important topics that the UGC has prescribed for educational institutions undertaking research. The topics are organized well and the concepts are explained in a simple and precise manner. A researcher from any disciple would find it easy to read and understand. The book offers a suitable solution to avoid plagiarism right from the moment one starts writing a research activity. Barring a few avoidable errors, the book gives extensive information on the relevant topics and improves overall understanding of research, ethics in research and publication, and publicizing research output using technological platforms. The book is an easy read for anybody who is interested in carrying out research activity. 


\section{References}

Yadav, S. K. (2020).Research and Publication Ethics. New Delhi: Ane Books Pvt. Ltd.

University Grants Commission. "Research and Publication Ethics."University Grants Commission, www.ugc.ac.in/pdfnews/9836633_Research-and-Publication-Ethics.pdf. (February 24, 2021. 